\title{
Study on Hepatitis B Protection Knowledge in Baoshan District of Yunnan Province
}

\author{
Yuan Ren \\ Baoshan College of Traditional Chinese Medicine, Baoshan City, Yunnan Province, 678000
}

Keywords: HBV; crowd; protection knowledge

\begin{abstract}
Objective: To understand the basic situation of hepatitis B protection knowledge and behavioral attitudes of hepatitis B patients in Baoshan District of Yunnan Province, and better, scientific and targeted work on infectious diseases. Methods: With the method of questionnaire survey, the database was established by using Epidata 3.1, and the statistical analysis of data was performed by using SPSS21.0. Results: 1 . The awareness rate of hepatitis B knowledge among the population: The surveyed subjects were different levels of people in Baoshan area, and the awareness rate of hepatitis B was $60.4 \%$. The awareness rate of hepatitis B for men and women was $62.6 \%$ and $59.8 \%$; the awareness rate of hepatitis B in urban population was higher than that in rural population. 2. Comparison of behavioral attitudes of the population to patients with hepatitis B: $26.6 \%$ of people with different genders are willing to live with hepatitis B patients, including 37.5\% of men and $23.6 \%$ of women; $38.2 \%$ of women The population was willing to continue to have a relationship with hepatitis B patients, of which $56.3 \%$ were male and $33.1 \%$ were female, which was statistically significant $(\mathrm{p}<0.05)$. On whether to agree to the detection of hepatitis $B$ virus before marriage, $93.0 \%$ of women and $86.6 \%$ of men are willing, and women's awareness of protection is higher than that of men. Men and women have similar views on whether to protect the privacy of hepatitis B patients. The attitudes of different ethnic groups to hepatitis B patients are basically the same. Although the awareness rate of hepatitis B in the Han population is higher than that of the minority population, there is no significant difference in the behavioral attitudes of hepatitis B patients between the Han population and the minority population. Conclusion: There is a defect in the awareness of hepatitis B knowledge among the population. It is necessary to carry out scientific and systematic publicity and health education on hepatitis B protection knowledge, so that people can better protect themselves and treat hepatitis B patients correctly and improve their humanities quality.
\end{abstract}

\section{Introduction}

Hepatitis B (abbreviated as hepatitis B) has seriously endangered human health and is a public problem that is urgently needed to be overcome in the world. Around the world, about 2 billion people have been or are infected with hepatitis B virus, and about 3.5-400 million hepatitis B patients have finally turned into chronic hepatitis B, which accounts for $6 \%$ of the total population. About one million people die each year from cirrhosis, liver failure, and primary liver cancer and other related diseases caused by HBV infection. It is transmitted through blood and body fluids, and it is a key infectious disease in China with chronic carrying status. According to the prevalence level of hepatitis B, the world is divided into three types: high, medium and low, and China is a highly epidemic area. Hepatitis B not only endangers the physical and mental health of human beings, but also causes serious economic burdens on families and society, and may even cause a series of social problems.

Since ancient times, people's understanding of hepatitis B has not been comprehensive enough, resulting in hepatitis B patients without a correct social status. Scientific and effective organization-related education is very important for the prevention of hepatitis $\mathrm{B}$. Therefore, to understand people's knowledge of hepatitis B and their attitudes and behaviors to patients, we can reasonably adopt relevant education. 


\section{Sample Source}

From September 2015 to October 2016, he was admitted to hospitals and blood stations in Baoshan area. The survey was completed by individuals, and the respondents completed the questionnaires themselves. A total of 1040 questionnaires were distributed and 1040 copies were collected. The recovery rate was $100 \%$, of which 1022 were valid questionnaires, and the effective rate was $98.3 \%$.

\section{Survey Method}

Samples were extracted using data sampling.

\section{Questionnaire Preparation}

Check the opinions of experts in the literature and ask for a sample questionnaire, including: (1) basic information: ethnicity, age, gender, address; (2) basic knowledge: selection of corresponding knowledge of hepatitis B, including: general knowledge, transmission routes, sources of infection, protective measures, etc.; Behavioral attitudes: attitudes and behaviors of hepatitis B patients or carriers in daily life, including: making friends, living and eating, etc.; (4) Ways to understand hepatitis B knowledge: ways to acquire knowledge.

\section{Questionnaire Analysis}

After the questionnaire survey, the questionnaires were statistically analyzed and analyzed. The database was created by using Epidata 3.1, double entry was made, and statistical analysis was performed by SPSS21.0.

\section{Results}

A total of 1040 questionnaires were distributed and 1040 copies were recovered. The recovery rate was $100 \%$, of which 1022 were valid questionnaires, and the effective rate was $98.3 \%$.

\subsection{Basic Situation.}

A total of 1040 questionnaires were distributed and 1040 copies were recovered. The recovery rate was $100 \%$, of which 1022 were valid questionnaires, and the effective rate was $98.3 \%$. Among them, 798 are women, accounting for 78.1\%; 224 are males, accounting for 21.9\%; 718 are Han, accounting for 70.3\%, and 304 are ethnic minorities, accounting for $29.7 \%$ (including 126 of Yi, $41.4 \%$, and 86 of Bai, accounting for 28.3\%). The other 92, accounting for 30.3\%); 469 people from towns, accounting for 45.9\%; 553 people from rural areas, accounting for $54.1 \%$.

Table 1 Distribution of survey population

\begin{tabular}{|llll|}
\hline Basic Information & & Number of people & ratio(\%) \\
\hline \multirow{2}{*}{ Gender } & Male & 224 & $21.9 \%$ \\
\cline { 2 - 4 } & Female & 798 & $78.1 \%$ \\
\hline \multirow{2}{*}{ Nationality } & Han nationality & 718 & $70.3 \%$ \\
\cline { 2 - 4 } & Minority & 304 & $29.7 \%$ \\
\hline \multirow{2}{*}{ Area } & Town & 469 & $45.9 \%$ \\
\cline { 2 - 4 } & Rural & 553 & $54.1 \%$ \\
\hline
\end{tabular}

\subsection{Mastery of Knowledge about Hepatitis B in Different Populations.}

Comparison of the awareness rate of hepatitis B among different ethnic groups.

The awareness rate of hepatitis B in the Han population was $61.5 \%$, and that in the minority population was $57.9 \%$. There was a difference in the awareness rate of hepatitis B among different ethnic groups $(\mathrm{p}<0.05)$. There are differences in the vaccination time of different ethnic groups at 
the time of 0, January, and June; there are differences in the use of condoms to block the knowledge of hepatitis B transmission, and the awareness rate of Han people is higher than that of ethnic minorities.

Table 2 Comparison of the awareness rates of different ethnic groups on hepatitis B

\begin{tabular}{|c|c|c|c|c|c|c|}
\hline $\begin{array}{l}\text { Serial } \\
\text { number }\end{array}$ & problem & $\begin{array}{l}\text { Correct } \\
\text { number of } \\
\text { people(\%) }\end{array}$ & $\begin{array}{l}\text { Han } \\
\text { nationality(\%) }\end{array}$ & minority(\%) & $X^{2}$ & $\mathrm{P}$ \\
\hline 1 & $\begin{array}{l}\text { Hepatitis B infection } \\
\text { source for patients and } \\
\text { carriers }\end{array}$ & 83.4 & 84.7 & 80.3 & 1.50 & $>0.05$ \\
\hline 2 & $\begin{array}{l}\text { The cause of hepatitis } B \text { is } \\
\text { a virus }\end{array}$ & 71.8 & 74.1 & 66.5 & 3.09 & $>0.05$ \\
\hline 3 & $\begin{array}{l}\text { Hepatitis B transmission is } \\
\text { mother-to-child } \\
\text { transmission }\end{array}$ & 90.8 & 91.4 & 89.5 & 0.46 & $>0.05$ \\
\hline 4 & $\begin{array}{l}\text { Hepatitis B } \\
\text { antibody is an effective } \\
\text { protective factor }\end{array}$ & 21.1 & 20.6 & 22.4 & 0.20 & $>0.05$ \\
\hline 5 & $\begin{array}{l}\text { Hepatitis B cannot be } \\
\text { completely cured }\end{array}$ & 48.7 & 48.2 & 50.0 & 0.14 & $>0.05$ \\
\hline 6 & $\begin{array}{l}\text { Prevention of hepatitis B } \\
\text { vaccination }\end{array}$ & 87.3 & 86.6 & 88.8 & 0.46 & $>0.05$ \\
\hline 7 & $\begin{array}{l}\text { Vaccination time is } 0 \\
\text { months, January, June }\end{array}$ & 36.2 & 39.3 & 29.0 & 4.93 & $<0.05$ \\
\hline 8 & $\begin{array}{l}\text { Use condoms to block } \\
\text { hepatitis B transmission }\end{array}$ & 44.0 & 47.1 & 36.8 & 4.54 & $<0.05$ \\
\hline
\end{tabular}

Comparison of the awareness rate of hepatitis B in different geographical groups. The awareness rate of hepatitis B in urban population was $65.9 \%$, and the awareness rate of hepatitis B in rural population was $59.8 \%$. There was no significant difference in the awareness rate of hepatitis $\mathrm{B}$ among different populations ( $>0.05$ ). The awareness rate of hepatitis $B$ virus caused by urban population was $84.1 \%$, while the awareness rate of rural population was $70.4 \%$, and that of urban areas was higher than that of rural areas $(\mathrm{p}<0.05)$; the rest were not statistically significant.

Table 3 Comparison of the awareness rate of hepatitis B in different regions

\begin{tabular}{|c|c|c|c|c|c|c|}
\hline $\begin{array}{l}\text { Serial } \\
\text { number }\end{array}$ & problem & $\begin{array}{l}\text { Correct number } \\
\text { of people(\%) }\end{array}$ & town(\%) & Rural(\%) & $X^{2}$ & $\mathrm{P}$ \\
\hline 1 & $\begin{array}{l}\text { Hepatitis } \text { B infection } \\
\text { source for patients and } \\
\text { carriers }\end{array}$ & 83.4 & 83.9 & 83.3 & 0.27 & $\begin{array}{l}>0 . \\
05\end{array}$ \\
\hline 2 & $\begin{array}{l}\text { The cause of hepatitis B is } \\
\text { a virus }\end{array}$ & 71.8 & 83.9 & 70.3 & 4.56 & $\begin{array}{l}<0 . \\
05\end{array}$ \\
\hline 3 & $\begin{array}{l}\text { Hepatitis B transmission is } \\
\text { mother-to-child } \\
\text { transmission }\end{array}$ & 90.8 & 94.6 & 90.1 & 1.20 & $\begin{array}{l}>0 . \\
05\end{array}$ \\
\hline 4 & $\begin{array}{l}\text { Hepatitis B } \\
\text { antibody is an effective } \\
\text { protective factor }\end{array}$ & 21.1 & 28.6 & 20.2 & 2.09 & $\begin{array}{l}>0 . \\
05\end{array}$ \\
\hline 5 & $\begin{array}{l}\text { Hepatitis B cannot be } \\
\text { completely cured }\end{array}$ & 48.7 & 55.4 & 47.9 & 1.11 & $\begin{array}{l}>0 . \\
05\end{array}$ \\
\hline 6 & $\begin{array}{l}\text { Prevention of hepatitis B } \\
\text { vaccination }\end{array}$ & 87.3 & 85.7 & 87.5 & 0.14 & $\begin{array}{l}>0 . \\
05\end{array}$ \\
\hline 7 & $\begin{array}{l}\text { Vaccination time is } 0 \\
\text { months, January, June }\end{array}$ & 36.2 & 39.3 & 35.8 & 0.26 & $\begin{array}{l}>0 . \\
05\end{array}$ \\
\hline 8 & $\begin{array}{l}\text { Use condoms to block } \\
\text { hepatitis B transmission }\end{array}$ & 44.0 & 55.4 & 42.9 & 3.16 & $\begin{array}{l}>0 . \\
05\end{array}$ \\
\hline
\end{tabular}




\subsection{Comparison of Behavioral Attitudes of People with Hepatitis B.}

Behavioral attitudes of different gender groups to patients with hepatitis B.

Before accepting the pre-marital hepatitis B test, he is willing to live with the hepatitis B patients. If the love object is the hepatitis B patients agree to continue the communication, the privacy of the hepatitis B patients should be protected. The gender differences are statistically significant $(\mathrm{p}<0.05)$. On pre-marital hepatitis B examination, $58.6 \%$ of women were higher than $48.4 \%$ of men; $37.5 \%$ of men and $23.6 \%$ of women lived with hepatitis B patients; $56.3 \%$ of men and $33.1 \%$ of women found that the object of love was hepatitis B patients agreed to continue Communication.

Behavioral attitudes of hepatitis B patients from different ethnic groups. The behavioral attitudes of different ethnic groups in patients with hepatitis B carriers and hepatitis B patients were not statistically significant in terms of whether they agreed to work together, eat, love, and live ( $\mathrm{p}>0.05)$.

Behavioral attitudes of people in different regions to hepatitis B patients. The privacy of patients with hepatitis B should be protected in different regions, and there is no statistical significance in treating whether to agree to work, eat, love, and residence ( $\mathrm{p}>0.05)$.

\section{Discussion}

Hepatitis B (abbreviated as hepatitis B) has seriously endangered human health and is a public problem that the world needs to solve urgently. Globally, about 2 billion people have been infected with HBV, and 350-400 million people have switched to chronic hepatitis B, accounting for 6\% of the world's total population. About 1 million people die each year from liver failure, cirrhosis, and primary liver cancer and other related diseases caused by HBV infection. It is transmitted through blood and body fluids, and it is a key infectious infectious disease in China with chronic carrying status. According to the prevalence level of hepatitis B, the world is divided into three types: high, medium and low, and China is a highly epidemic area. Hepatitis B not only endangers the physical and mental health of human beings, but also causes serious economic burdens on families and society, and may even cause a series of social problems. It is very important to have a planned, scientific organization related knowledge education to protect hepatitis $\mathrm{B}$.

Since the introduction of hepatitis B vaccine into a class of vaccine in China since 1992, the vaccination rate of neonates and school-age children has gradually increased, and the infection rate has been declining. However, adults lack prevention awareness, and vaccination work is still not ideal, making prevention of hepatitis B difficult to implement, and more and more cases. Hepatitis $B$ virus patients and carriers should be further investigated to develop different vaccination programs for different types of infections, to raise people's awareness and strengthen publicity.

Although the population has certain knowledge and understanding of hepatitis B protection knowledge, the degree of understanding is limited, the understanding problems are different, and the structure of knowledge is not comprehensive and systematic. The total awareness rate of protection knowledge is $60.4 \%$, but they are lower than the requirements of more than $80 \%$ of the 2006-2010 National Hepatitis B Prevention and Control Plan. Through questionnaire survey, it can be found that hepatitis B vaccination time is 0 months, January and June. Hepatitis B surface antibody is an effective protective factor. The use of condom can block the spread of hepatitis B and hepatitis B can not be completely cured. The color awareness rate is not high. There was a difference in the awareness rate of hepatitis B among different gender groups $(p<0.05)$, and both males and females had certain protective awareness. There is also a difference in the awareness rate of hepatitis $\mathrm{B}$ among different ethnic groups $(\mathrm{p}<0.05)$, which may be related to the national language environment. The Han population has certain advantages in language and acceptance. The awareness rate of hepatitis B in different regions is not statistically significant, indicating that the defense knowledge of hepatitis B is very powerful, and both urban and rural areas can acquire knowledge through many channels.

According to Table 1-3, 26.6\% of people with different genders are willing to live with hepatitis 
B patients, including $37.5 \%$ of men and $23.6 \%$ of women; $38.2 \%$ of people are willing to continue In association with hepatitis B patients, $56.3 \%$ were male and $33.1 \%$ were female, which was statistically significant $(\mathrm{p}<0.05)$. On whether to agree to the detection of hepatitis $\mathrm{B}$ virus before marriage, $93.0 \%$ of women and $86.6 \%$ of men are willing, and women's awareness of protection is higher than that of men. Men and women have similar views on whether to protect the privacy of hepatitis B patients. The behavioral attitudes of different ethnic groups to patients with hepatitis B were basically the same. Combined with Table 2, it was found that although the awareness rate of hepatitis B in the Han population was higher than that of the minority population, there was no significant difference in the behavioral attitudes of hepatitis B patients between the Han population and the minority population.

From the way to obtain knowledge of hepatitis B protection, it was found that the people mainly learned about the protection of hepatitis B through television, buns, networks and doctors' notifications, and secondly from the education and books of the school.

From the survey results, it is found that different ages, education, occupational status and regional status are the main influencing factors affecting the recognition of hepatitis $\mathrm{B}$ in adults in Baoshan area. Young people's understanding of hepatitis B is higher than that of middle-aged and elderly people. Previous studies have found that understanding and awareness of hepatitis B in urban and rural areas does not use age as an influencing factor. The results of the education level show that the level of understanding and cognition of hepatitis B is very high in the level of education. The understanding and cognition of hepatitis B in different occupational conditions are also very different. The public officials have a higher level of understanding and awareness of hepatitis $\mathrm{B}$, while the relative awareness of migrant workers entering the city is relatively low. The work of public officials is relatively stable, and the access to knowledge is easier, while the migrant workers entering the city are more mobile and the access to knowledge is more difficult. Therefore, the popularization of the knowledge of hepatitis B protection among rural population should be strengthened. The level of income also determines the understanding and cognitive ability of hepatitis B. The survey shows that the level of income also determines the level of cognitive ability. This is due to regional differences.

\section{References}

[1] Sara Ashtari, Mohamad Amin Pourhoseingholi, Afsaneh Sharifian, Mohamad Reza Zali. Hepatocellular carcinoma in Asia: Prevention strategy and planning [J]. World Journal of Hepatology. 2015(12).

[2] Mahmoud Reza Pourkarim, Samad Amini-Bavil-Olyaee,Fuat Kurbanov, Marc Van Ranst, Frank Tacke. Molecular identification of hepatitis B virus genotypes/subgenotypes: Revised classification hurdles and updated resolutions[J].World Journal of Gastroenterology.2014(23).

[3] Wei-Cheng Liu, Quan-Yan Liu. Molecular mechanisms of gender disparity in hepatitis B virus-associated hepatocellular carcinoma [J].World Journal of Gastroenterology.2014 (20).

[4] Wan-Yee Lau, Eric C.H.Lai. Hepatocellular carcinoma: current management and recent advances [J].Hepatobiliary \& Pancreatic Diseases International.2008 (03).

[5] Joachim Lupberger, Eberhard Hildt. Hepatitis B virus-induced oncogenesis[J]. World Journal of Gastroenterology. 2007(01).

[6] Gerald C Kimbi,Anna Kramvis,Michael C Kew.Integration of hepatitis B virus DNA into chromosomal DNA during acute hepatitis B[J].World Journal of Gastroenterology.2005(41).

[7] Torre, Freddie Bray, Rebecca L. Siegel, Jacques Ferlay, Joannie Lortet-Tieulent, Ahmedin Jemal. Lindsey A.Global cancer statistics, 2012[J].CA:A Cancer Journal for Clinicians.2015 (2).

[8] Marc Ringelhan, Tracy O’Connor, Ulrike Protzer, Mathias Heikenwalder. The direct and indirect roles of HBV in liver cancer: prospective markers for HCC screening and potential therapeutic targets[J].J.Pathol.2015 (2). 
[9] Zhang Ronglian, Wang Meiying, Ren Kunhai et al. Traceability of HBV-positive genotypes in neonatal cord blood[J].Chinese Journal of Maternal and Child Health,2013,28(35):5855-5858.

[10] Gu Xibing, Zhu Yinfang, Wang Wei et al. Relationship between hepatitis B virus genotype and follicular helper T lymphocytes and its significance[J]. Chinese Journal of Infectious Diseases, 2013, 31(1): 46-48.

[11] Chen Hemin, Shao Guohui. Discussion on the treatment of chronic hepatitis B with nucleoside and nucleotide drugs[J].Journal of Clinical Hepatology,2016(07).

[12] Zhu Danyan, Wang Dandan, Wang Dan. Research progress in drug treatment of hepatitis B [J]. Strait Pharmaceutical. 2016(04).

[13] Zou Naifa, Zou Xiaochun, Chen Huahui et al. Analysis of the relationship between risk factors and age of liver cancer in a certain area of Guangdong[J]. China Health Industry. 2016(28).

[14] Lin Yilan, Lin Fusheng. Epidemiological analysis of liver cancer death in Xiamen residents from 2004 to 2014 [J]. Chinese Journal of Chronic Disease Prevention and Control. 2016(07). 